\title{
Dietary selenium and major depression: a nested case-control study
}

\author{
Julie A. Pasco ${ }^{a, b, *}$, Felice N. Jacka ${ }^{a, c}$, Lana J. Williams ${ }^{a, c}$, \\ Melinda Evans-Cleverdon ${ }^{d}$, Sharon L. Brennan ${ }^{a, b}$, Mark A. Kotowicz ${ }^{a, b}$, \\ Geoffrey C. Nicholson ${ }^{\mathrm{e}}$, Madeleine J. Ball ${ }^{\mathrm{d}}$, Michael Berk ${ }^{\mathrm{a}, \mathrm{c}, \mathrm{f}, \mathrm{g}}$
}

\author{
a School of Medicine, Deakin University, Geelong, Victoria 3220, Australia \\ b NorthWest Academic Centre, Department of Medicine, The University of Melbourne, St Albans, Victoria 3021, Australia \\ c Department of Psychiatry, The University of Melbourne, Parkville, Victoria 3010, Australia \\ d School of Human Life Sciences, University of Tasmania, Launceston, Tasmania 7250, Australia \\ e Rural Clinical School, School of Medicine, The University of Queensland, Toowoomba, Queensland 4350, Australia \\ f ORYGEN Youth Health Research Centre, Centre for Youth Mental Health, The University of Melbourne, Parkville, Victoria 3052, \\ Australia \\ g The Mental Health Research Institute of Victoria, Parkville, Victoria 3052, Australia \\ Available online 30 January 2012
}

\section{KEYWORDS \\ Antioxidant; \\ Diet; \\ Epidemiology; \\ Major depressive \\ disorder; \\ Dietary selenium; \\ Risk factor; \\ Women}

\begin{abstract}
Summary
Objectives and methods: Alterations in redox biology are established in depression; however, there are no prospective epidemiological data on redox-active selenium in depression. We aimed to determine if low levels of dietary selenium are associated with an increased risk for de novo major depressive disorder (MDD). In this nested case-control study, women aged 20 years or more were identified from a randomly selected cohort being followed prospectively for the Geelong Osteoporosis Study. Cases were individuals with incident MDD, identified using the Structured Clinical Interview for DSM-IV-TR (SCID-I/NP); controls had no such history. Dietary selenium intake was measured using a food frequency questionnaire at baseline, together with anthropometric and lifestyle measures.

Results: Eighteen women who developed de novo MDD were classified as cases; there were 298 controls. Low dietary selenium intakes increased the likelihood of developing MDD; OR 2.74 $(95 \% \mathrm{Cl}$ 0.95-7.89). After adjusting for age and SES, compared with a high selenium intake, a low intake $(<8.9 \mu \mathrm{g} / \mathrm{MJ} /$ day $)$ was associated with an approximate trebling of the likelihood
\end{abstract}

\footnotetext{
The study was funded, in part, by the Victorian Health Promotion Foundation and the NHMRC, but they played no part in the design or conduct of the study; collection, analysis, and interpretation of the data; or in the writing of the manuscript or in the decision to submit the manuscript for publication. Felice Jacka and Sharon Brennan are supported by NHMRC Early Career Fellowships (628912 and 1012472 , respectively). Michael Berk has received Grant/Research Support from the Stanley Medical Research Foundation, MBF, NHMRC, Beyond Blue, Geelong Medical Research Foundation, Bristol Myers Squibb, Eli Lilly, Glaxo SmithKline, Organon, Novartis, Mayne Pharma, Servier and Astra Zeneca. He has been a paid consultant for Astra Zeneca, Bristol Myers Squibb, Eli Lilly, Glaxo SmithKline, Janssen Cilag, Lundbeck and Pfizer and a paid speaker for Astra Zeneca, Bristol Myers Squibb, Eli Lilly, Glaxo SmithKline, Janssen Cilag, Lundbeck, Merck, Organon, Pfizer, Sanofi Synthelabo, Solvay and Wyeth.

* Corresponding author at: Barwon Epidemiology and Biostatistics Unit (Barwon Health), School of Medicine, Deakin University,

PO Box 281, Geelong, Victoria 3220, Australia. Tel.: +61 35226 7393; fax: +61 352465165.

E-mail address: juliep@barwonhealth.org.au (J.A. Pasco).
} 
for developing de novo MDD; OR 2.95 (95\% CI 1.00-8.72). Smoking, alcohol consumption and physical activity did not confound the association.

Conclusion: These data suggest that lower dietary selenium intakes are associated with an increased risk of subsequent de novo MDD. We propose that selenium's function as an antioxidant, and as a constituent of selenoproteins that are important in redox homeostasis, warrants further investigation as a risk factor for depression, and suggest a potentially novel modifiable factor in the primary prevention and management of depression.

(c) 2012 Elsevier Ltd. All rights reserved.

\section{Introduction}

Selenium is an essential micronutrient in humans, although it is toxic in large doses. ${ }^{1}$ Selenium is incorporated into selenoproteins, major forms of which are the glutathione peroxidases and thioredoxin reductases. These are important antioxidants that reduce hydrogen peroxide to water, and reduce the damaging lipid hydroperoxides to alcohol. ${ }^{1,2}$ Selenium inhibits the activation of NF-kappaB by modulating the expression of selenoprotein genes and suppressing $\mathrm{C}$-reactive protein production, leading to attenuation of inflammation. ${ }^{3}$ Consequently, selenium may play a role in inflammatory disease, and might modulate clinical outcomes in infective and inflammatory illnesses.

Depression is becoming recognised as an inflammatory disorder, accompanied by an accumulation of highly reactive oxygen species that overwhelm usual defensive physiological processes. ${ }^{4-11}$ Several indicators support a role for selenium in normal brain function. During times of selenium deficiency, there is preferential storage of selenium in the brain. ${ }^{12}$ Selenium has significant modulatory effects on dopamine ${ }^{13-15}$ and dopamine plays a role in the pathophysiology of depression and other psychiatric illnesses. ${ }^{16,17}$ Diminished levels of selenium in the brain are associated with cognitive decline ${ }^{18}$ and Alzheimer's disease. ${ }^{19}$ Selenium supplementation has been linked with improvements in mood 20,21 and protection against postpartum depression. ${ }^{22}$

What is unclear is if low dietary selenium is a risk factor for the development of depression. In recognition of selenium's biological activity, we hypothesised that low levels of dietary selenium would be associated with an increased risk of major depressive disorder (MDD) in a representative population-based sample of women.

\section{Methods}

\section{Study subjects}

This study focuses on women enrolled in the Geelong Osteoporosis Study (GOS). A cohort of 1494 women was selected at random from the Commonwealth electoral rolls for the Barwon Statistical Division in south-eastern Australia, enrolled in the period 1994-1997 with $77.1 \%$ participation ${ }^{23}$ and followed prospectively for a decade. At baseline, selenium intakes were evaluated for 575 randomly selected women aged 20-89 years; 19 individuals who had anomalous responses on dietary questionnaires were excluded (17 were incomplete or incorrectly indicated multiple responses to frequency of food consumption and two were outliers with excessively high selenium intakes). Three hundred and sixteen of the women with valid dietary questionnaires also participated in a psychiatric interview at the 10-year follow-up, fulfilling eligibility criteria for this analysis. Barwon Health Human Research Ethics Committee approved the study, and written consent was obtained from all participants.

\section{Data}

The Structured Clinical Interview for DSM-IV-TR Research Version, Non-patient edition (SCID-I/NP) was used to identify those with a lifetime history of MDD, and to determine age of onset. Women identified as having experienced de novo MDD in the years following baseline were cases; those with no such history were controls. Trained personnel conducted psychiatric interviews.

The exposure of interest was dietary selenium intake. Detailed semi-quantitative food frequency questionnaires were used to capture responses on 359 foods. ${ }^{24}$ The questionnaire records both the frequency (number of times the foods were consumed daily, weekly, monthly or more rarely) and portion size (standard or specified other) of foods consumed at each meal time (breakfast, lunch, dinner and between meal snacks). Additionally, the questionnaire sought details about food preparation and cooking methods used. The reproducibility of this meal-based questionnaire had been tested previously. ${ }^{24}$ Selenium intake was individually estimated from available food data according to the Australia and New Zealand Food Authority (ANZFA). These data were available for raw foods including most fruits and vegetables, raw fish and meats, wheat and prepared foods such as bread, biscuits, breakfast cereals and cooked meats; otherwise, selenium contents were estimated from the United States Department of Agriculture (USDA) databank. ${ }^{25}$

Body weight and height were measured and body mass index (BMI) calculated as weight/height ${ }^{2}\left(\mathrm{~kg} / \mathrm{m}^{2}\right)$. Other lifestyle exposures such as tobacco smoking, alcohol consumption, and physical activity were documented by self-report at the baseline visit. Smoking was described as ever/never; alcohol use recognised if consumed daily; habitual physical activity level described as very active if vigorous exercise was performed regularly; and socio-economic status (SES) ascertained using the Socio-Economic Index For Areas (SEIFA) values based on Census Collection District data from the Australian Bureau of Statistics. SEIFA values were used to derive an Index of Occupation and Education (IOE). This was categorised into quintiles of IOE for the study region. Quintiles 1 and 2 (low), and 4 and 5 were combined because of small numbers to create three categories of SES, namely low, medium and high. 


\section{Statistics}

Daily selenium intakes were expressed as selenium $(\mu g)$ per total energy intake (MJ). Selenium intakes ( $\mu \mathrm{g} / \mathrm{MJ} /$ day) were categorised as high and low, corresponding to groups above and below the median. Standard descriptive statistics were used to characterise and compare cases and controls. Selenium and energy intakes, together with adjusted selenium intakes ( $\mu \mathrm{g} / \mathrm{MJ} / \mathrm{day}$ ) were skewed, but were normalised by natural log transformation. Logistic regression models were used to determine the association between exposure to high or low selenium intakes and the likelihood of developing MDD during the period of follow-up. Smoking, alcohol use, physical activity, age and SES were investigated as confounders and effect modifiers. Statistical analyses were performed using Stata (release 9.0, StataCorp, College Station, TX) and Minitab (version 15; Minitab, State College, PA).

\section{Results}

The median selenium intake was $71.2 \mu \mathrm{g} /$ day (interquartile range, IQR, 55.9-87.0). One hundred and one women (32.0\%) had intakes below the Australian recommended daily intake of $60 \mu \mathrm{g} / \mathrm{day}$; no toxic levels were found. There was a strong correlation between selenium intake and energy intake (both log transformed, $r=0.7, p<0.001$ ). Median selenium intake corrected for energy intake was $8.9 \mu \mathrm{g} / \mathrm{MJ} /$ day (IQR 7.7-10.5). Subject characteristics are shown for cases and controls in Table 1. No differences in socio-demographic or lifestyle factors were detected between cases and controls.

Eighteen women developed de novo MDD over the study period and were classified as cases; there were 298 controls. A low selenium intake was associated with greater odds for de novo MDD; OR $2.74(95 \% \mathrm{Cl} 0.95-7.89), p=0.06$. After adjusting for age and SES, the OR was $2.95(95 \% \mathrm{Cl}$ $1.00-8.72), p=0.05$. These data provide moderate evidence to reject the null hypothesis of no difference in the likelihood of developing MDD between the groups with high and low selenium intakes. Further adjustment for smoking, alcohol use and physical activity did not impact on the point estimate.

\section{Discussion}

Our results support the hypothesis that lower dietary selenium intakes increase the risk of subsequent de novo MDD. Selenium-rich foods include brazil nuts, kidneys, liver, fish and eggs; however, wheat products, fish, vegetables, beef and fruit provide most of the daily selenium intake among Australian women living in the study region. ${ }^{25}$ These findings are in accordance with previously published data showing that diets rich in wholefoods are associated with a reduced likelihood for depression and anxiety. ${ }^{26,27}$ Although the median selenium intake of women in this study was in accordance with the National Health and Medical Research Council (Australia) guidelines, it is noteworthy that onethird of the women consumed less than the recommended daily intake. The strong correlation between daily total energy and selenium intakes suggests that energy-restricted diets may increase the risk of selenium insufficiency

The characteristics of the study require noting in interpreting the results. As we were limited by small numbers, selenium intakes were dichotomised rather than being categorised into smaller groups, such as tertiles or quartiles; further research is required to investigate dose and/or threshold effects. The potential for differential recall bias in the food frequency questionnaire responses has been minimised by nesting the study within a larger prospective cohort study and by recording dietary histories before the onset of MDD. As depression can impact on self-care and dietary patterns, it was important to exclude women with prior depression; however, the possibility of reverse causality cannot be definitively excluded. Psychiatric interviews were administered by trained personnel who were blinded to baseline dietary histories. Also, changes in dietary intakes of selenium over the period of follow-up have not been identified; misclassification of selenium intakes would likely attenuate the reported association between selenium intake and likelihood of MDD. Selenium is found in a variety of foods and, as the selenium content varies according to the selenium content of soil, ${ }^{28}$ we cannot assume that the selenium intakes have been accurately calculated for this region. Variation in selenium content is particularly evident among plant food sources, where much of the selenium is in the form of selenomethionine, selenocysteine or selenocysteine metabolites, but there is less variation in the selenium content of muscle meats and seafood. Findings from this study may not be generaliseable to populations drawn from other regions and, furthermore, may not be applicable to men.

In a double-blind US study involving 11 men confined to a metabolic unit for 120 days, low pre-baseline dietary selenium was associated with poor mood. ${ }^{29}$ Subsequent intervention with a high selenium diet of $356 \mu \mathrm{g} /$ day for 99 days, resulted in no improvement in mood; however, it is possible that the psychological effects of being confined may have negated any beneficial effects of the selenium supplementation. In another US study of 30 men allocated to either a low or high selenium diet ( $32.6 \mathrm{vs}$. $226.5 \mu \mathrm{g} / \mathrm{day})$, mood deteriorated with the low diet and improved with the high diet. ${ }^{20}$ In a double blind cross-over trial of 50 British individuals, selenium supplementation with $100 \mu \mathrm{g} /$ day for five weeks evoked improvement in depression, with a greater effect among those with poorer dietary selenium intakes. ${ }^{21}$ In contrast, a larger randomised-controlled trial among 501 elderly volunteers in the UK showed no such effect. $^{30}$

The glutathione antioxidant system is implicated in the pathophysiology of mood disorders. ${ }^{7}$ Selenium is a critical cofactor for the enzyme, glutathione peroxidase, ${ }^{31}$ as well as the thioredoxin antioxidant system. Further support for a role of the glutathione system in psychopathology comes from clinical trials involving treatment with $\mathrm{N}$-acetyl cysteine (NAC), a precursor of cysteine and glutathione. ${ }^{32}$ Recent double-blind randomised placebo controlled trials of NAC have shown improvements in depressive symptoms in bipolar disorder ${ }^{33,34}$ and schizophrenia. ${ }^{32,35}$

In addition to selenium's putative protective role against neurodegeneration, ${ }^{18,19}$ selenium has been implicated in immunoprotection ${ }^{36}$ and cancer prevention. ${ }^{37}$ Because 
Table 1 Characteristics are shown for cases (with MDD) and controls. Data are shown as mean ( $\pm S D$ ), median (interquartile range, IQR) or number (\%).

\begin{tabular}{llll}
\hline & Cases $(n=18)$ & Controls $(n=298)$ & $P$-Value \\
\hline Age (year), median (IQR) & $49.5(37.0-63.5)$ & $48.4(35.3-61.4)$ & 0.6 \\
Energy intake $(\mathrm{MJ} /$ day), median $(\mathrm{IQR})$ & $7.93(6.30-9.42)$ & $7.95(6.32-9.37)$ & 0.9 \\
Weight $(\mathrm{kg})$, mean $( \pm \mathrm{SD})$ & $70.6( \pm 10.6)$ & $68.1( \pm 12.5)$ & 0.4 \\
Height $(\mathrm{cm})$, mean $( \pm \mathrm{SD})$ & $163.1( \pm 7.6)$ & $161.7( \pm 6.1)$ & 0.3 \\
Body mass index $\left(\mathrm{kg} / \mathrm{m}^{2}\right)$, mean $( \pm \mathrm{SD})$ & $26.6( \pm 4.5)$ & $94(31.5 \%)$ & 0.6 \\
Smokers, $n(\%)$ & $6(33.3 \%)$ & $25(8.4 \%)$ & 0.9 \\
Daily alcohol use, $n(\%)$ & $0(0.0 \%)$ & $37(12.4 \%)$ & 0.4 \\
Physically active, $n(\%)$ & $3(16.7 \%)$ & & 0.5 \\
Socio-economic status, $n(\%)$ & & $88(29.5 \%)$ & 0.2 \\
$\quad$ Low & $9(50.0 \%)$ & $69(23.2 \%)$ & $141(47.3 \%)$ \\
Medium & $4(22.2 \%)$ & $5(27.8 \%)$ & \\
High & &
\end{tabular}

immunological dysfunction and cancer are characterised by oxidative stress, it is hypothesised that selenium's biological activity as an antioxidant could underpin these findings as well.

In conclusion, our data suggest that a lower dietary selenium intake is associated with an increased risk of de novo MDD, supporting a role for selenium in mood. Further research focused on the implications of low selenium intakes in other populations is warranted and may provide a rationale for future randomised controlled clinical trials to assess potential benefits of selenium (either alone or in combination with other key nutrients) as a novel modifiable factor in the primary prevention and management of depression.

\section{Conflict of interest statement}

None of the other authors has any conflicts of interest, including specific financial interests and relationships and affiliations relevant to the subject matter or materials discussed in the manuscript.

\section{Acknowledgements}

The study was supported by the Victorian Health Promotion Foundation and the NHMRC (Australia).

\section{References}

1. Rayman MP. The importance of selenium to human health. Lancet 2000;356:233-41.

2. Holben DH, Smith AM. The diverse role of selenium within selenoproteins: a review. J Am Diet Assoc 1999;99:836-43.

3. Duntas LH. Selenium and inflammation: underlying antiinflammatory mechanisms. Horm Metab Res 2009;41:443-7.

4. Maes M, Ruckoanich P, Chang YS, Mahanonda N, Berk M. Multiple aberrations in shared inflammatory and oxidative \& nitrosative stress (IO\&NS) pathways explain the co-association of depression and cardiovascular disorder (CVD), and the increased risk for CVD and due mortality in depressed patients. Prog NeuroPsychopharmacol Biol Psychiatry 2011;35:769-83.
5. Maes M, Galecki P, Chang YS, Berk M. A review on the oxidative and nitrosative stress (O\&NS) pathways in major depression and their possible contribution to the (neuro)degenerative processes in that illness. Prog Neuro-Psychopharmacol Biol Psychiatry 2011;35:676-92.

6. Ng F, Berk M, Dean O, Bush Al. Oxidative stress in psychiatric disorders: evidence base and therapeutic implications. Int $J$ Neuropsychopharmacol 2008;11:851-76.

7. Berk M, Ng F, Dean O, Dodd S, Bush Al. Glutathione: a novel treatment target in psychiatry. Trends Pharmacol Sci 2008;29:346-51.

8. Herken H, Gurel A, Selek S, Armutcu F, Ozen ME, Bulut M, et al. Adenosine deaminase, nitric oxide, superoxide dismutase, and xanthine oxidase in patients with major depression: impact of antidepressant treatment. Arch Med Res 2007;38:247-52.

9. Sarandol A, Sarandol E, Eker SS, Erdinc S, Vatansever E, Kirli S. Major depressive disorder is accompanied with oxidative stress: short-term antidepressant treatment does not alter oxidativeantioxidative systems. Hum Psychopharmacol 2007;22: 67-73.

10. Khanzode SD, Dakhale GN, Khanzode SS, Saoji A, Palasodkar R. Oxidative damage and major depression: the potential antioxidant action of selective serotonin re-uptake inhibitors. Redox Rep 2003;8:365-70.

11. Bilici M, Efe H, Koroglu MA, Uydu HA, Bekaroglu M, Deger O. Antioxidative enzyme activities and lipid peroxidation in major depression: alterations by antidepressant treatments. J Affect Disorders 2001;64:43-51.

12. Whanger PD. Selenium and the brain: a review. Nutr Neurosci 2001;4:81-97.

13. Machado MS, Rosa RM, Dantas AS, Reolon GK, Appelt HR, Braga AL, et al. An organic selenium compound attenuates apomorphine-induced stereotypy in mice. Neurosci Lett 2006;410:198-202.

14. Imam SZ, el-Yazal J, Newport GD, Itzhak Y, Cadet JL, Slikker $\mathrm{Jr} \mathrm{W}$, et al. Methamphetamine-induced dopaminergic neurotoxicity: role of peroxynitrite and neuroprotective role of antioxidants and peroxynitrite decomposition catalysts. Ann N Y Acad Sci 2001;939:366-80.

15. Castano A, Ayala A, Rodriguez-Gomez JA, Herrera AJ, Cano J, Machado A. Low selenium diet increases the dopamine turnover in prefrontal cortex of the rat. Neurochem Int 1997;30:549-55.

16. Berk M, Dodd S, Kauer-Sant'anna M, Malhi GS, Bourin M, Kapczinski F, et al. Dopamine dysregulation syndrome: implications for a dopamine hypothesis of bipolar disorder. Acta Psychiatr Scand Suppl 2007;(434):41-9. 
17. Malhi GS, Berk M. Does dopamine dysfunction drive depression? Acta Psychiatr Scand Suppl 2007;(433):116-24.

18. Ishrat T, Parveen K, Khan MM, Khuwaja G, Khan MB, Yousuf S, et al. Selenium prevents cognitive decline and oxidative damage in rat model of streptozotocin-induced experimental dementia of Alzheimer's type. Brain Res 2009;1281:117-27.

19. Cardoso BR, Ong TP, Jacob-Filho W, Jaluul O, Freitas MI, Cozzolino SM. Nutritional status of selenium in Alzheimer's disease patients. Br J Nutr 2010;103:803-6.

20. Finley JW, Penland JG. Adequacy or deprivation of dietary selenium in healthy men: clinical and psychological findings. $J$ Trace Elem Exp Med 1998;11:1-27.

21. Benton D, Cook R. The impact of selenium supplementation on mood. Biol Psychiatry 1991;29:1092-88.

22. Mokhber N, Namjoo M, Tara F, Boskabadi H, Rayman MP, Ghayour-Mobarhan M, et al. Effect of supplementation with selenium on postpartum depression: a randomized doubleblind placebo-controlled trial. J Matern Fetal Neonatal Med 2011;24:104-8.

[23].Pasco JA, Nicholson GC, Kotowicz MA. Cohort profile: Geelong Osteoporosis Study. Int J Epidemiol [Epub ahead of print].

24. Wheeler C, Rutishauser I, Conn J, O'Dea K. Reproducibility of a meal-based food frequency questionnaire. Eur $\mathrm{J}$ Clin Nutr 1994;48:795-809.

25. Cleverdon M, Pasco JA, Ball MJ. Daily dietary selenium intake of a randomly selected population of Victorian women: age group differences and food sources. Asia Pac J Clin Nutr 2006;15:S119.

26. Jacka FN, Pasco JA, Mykletun A, Williams LJ, Hodge AM, O'Reilly SL, et al. Association of Western and traditional diets with depression and anxiety in women. Am J Psychiatry 2010;167:305-11.

27. Akbaraly TN, Brunner EJ, Ferrie JE, Marmot MG, Kivimaki M, Singh-Manoux A. Dietary pattern and depressive symptoms in middle age. Br J Psychiatry 2009;195:408-13.

28. Johnson CC, Fordyce FM, Rayman MP. Symposium on 'Geographical and geological influences on nutrition': factors controlling the distribution of selenium in the environment and their impact on health and nutrition. Proc Nutr Soc 2010;69:119-32.

29. Hawkes WC, Hornbostel L. Effects of dietary selenium on mood in healthy men living in a metabolic research unit. Biol Psychiatry 1996;39:121-8.

30. Rayman M, Thompson A, Warren-Perry M, Galassini R, Catterick $\mathrm{J}$, Hall $\mathrm{E}$, et al. Impact of selenium on mood and quality of life: a randomized, controlled trial. Biol Psychiatry 2006;59: $147-54$.

31. Czuczejko J, Zachara BA, Staubach-Topczewska E, Halota W, Kedziora J. Selenium, glutathione and glutathione peroxidases in blood of patients with chronic liver diseases. Acta Biochim Pol 2003;50:1147-54.

32. Berk M, Copolov D, Dean O, Lu K, Jeavons S, Schapkaitz I, et al. $\mathrm{N}$-acetyl cysteine as a glutathione precursor for schizophrenia-a double-blind, randomized, placebo-controlled trial. Biol Psychiatry 2008;64:361-8.

33. Magalhaes PV, Dean OM, Bush Al, Copolov DL, Malhi GS, Kohlmann $\mathrm{K}$, et al. $\mathrm{N}$-acetyl cysteine add-on treatment for bipolar II disorder: a subgroup analysis of a randomized placebocontrolled trial. J Affect Disorders 2011;129:317-20.

34. Berk M, Copolov DL, Dean O, Lu K, Jeavons S, Schapkaitz I, et al. $\mathrm{N}$-acetyl cysteine for depressive symptoms in bipolar disorder-a double-blind randomized placebo-controlled trial. Biol Psychiatry 2008;64:468-75.

35. Berk M, Munib A, Dean O, Malhi GS, Kohlmann K, Schapkaitz I, et al. Qualitative methods in early-phase drug trials: broadening the scope of data and methods from an RCT of N-acetylcysteine in schizophrenia. J Clin Psychiatry 2010;72:909-13.

36. Spallholz JE, Boylan LM, Larsen HS. Advances in understanding selenium's role in the immune system. Ann N Y Acad Sci 1990;587:123-39.

37. Rayman MP. Selenium in cancer prevention: a review of the evidence and mechanism of action. Proc Nutr Soc 2005;64: $527-42$. 